Arq. Bras. Med. Vet. Zootec., v.64, n.5, p.1137-1144, 2012

\title{
Aspectos tomográficos da coluna cervical de equinos
}

\author{
[Tomographic imaging of the cervical spine of horses] \\ L.P. Souza, V.M.V. Machado, R.V. Santos, F.C. Evangelista, L.C. Vulcano
}

Faculdade de Medicina Veterinária e Zootecnia - Universidade Estadual Paulista - Botucatu, SP

\section{RESUMO}

Descreveu-se a anatomia da região cervical de equinos adultos, com base em imagens obtidas no exame de tomografia computadorizada helicoidal realizado em peças anatômicas de equinos adultos. A tomografia computadorizada foi o método de imagem diagnóstica de escolha e possibilita as reconstruções de imagens tridimensionais e em outros planos anatômicos, como sagital e coronal. Todas as imagens foram adquiridas e avaliadas em filtro e janela para tecido ósseo. Observaram-se diferenças anatômicas e as particularidades normais das vértebras, principalmente da região occipitoatlantoaxial, a qual apresenta maior incidência de alterações.

Palavras-chave: cavalo, tomografia computadorizada helicoidal, coluna cervical

\begin{abstract}
The anatomy of the cervical spine of mature horses based on images obtained with a helical computed tomography examination performed on anatomic specimens was studied. Computed tomography was the diagnostic imaging method of choice and allowed three-dimensional reconstructions of images and other anatomical planes, such as coronal and sagittal. All images were acquired and evaluated in the filter and window to bone tissue. It was possible to demonstrate the anatomical differences and peculiarities of the normal vertebrae, particularly the occipito-atlantoaxial region, which has a higher incidence of changes to assist in the visualization of any change of the bone pattern on CT studies.
\end{abstract}

Keywords: horse, helical CT, cervical

\section{INTRODUÇÃO}

O exame clínico da região cervical dos equinos é um desafio para os clínicos na determinação precisa do local da lesão, utilizando-se somente o exame físico (Haussler, 2000; Berg et al., 2002; Fonseca et al., 2006). A medicina equina ainda não alcançou o progresso que já se obteve na medicina humana no diagnóstico das afecções cervicais. Entretanto, os recentes avanços no diagnóstico por imagem na medicina veterinária incrementaram as possibilidades de investigação diagnóstica dos sinais clínicos relacionados à região cervical (Mayhew, 1999; Dyson, 2003).

A radiografia convencional, embora muito utilizada para traumas e malformações congênitas, possui baixa especificidade e sensibilidade para avaliação de afecções cervicais comuns em equinos, como a síndrome Wobbler (Buttler et al., 2000; Rush e Grady, 2002; Mattoon, 2007; Dimock e Puchalski, 2010), decorrente da sobreposição das estruturas cervicais. A tomografia computadorizada possibilita a visibilização em diversos planos anatômicos sem a sobreposição das estruturas adjacentes às vértebras. Constitui o método de escolha na medicina humana para imagens de lesões ósseas vertebrais, demonstrando hoje valioso auxílio para uma investigação mais acurada das lesões vertebrais em cães (Gollob et al., 2002; Dyson, 2003; MacKay, 2006; Withers et al., 2009).

O estudo anatômico da região cervical de equinos a partir da obtenção de imagens tomográficas torna-se relevante em razão das

Recebido em 9 de agosto de 2011

Aceito em 11 de setembro de 2012

E-mail: li.pasini.vet@gmail.com 
particularidades e variações anatômicas normais encontradas nas vértebras desta espécie, as quais podem ser interpretadas erroneamente quando desconhecidas. Tendo em vista a alta incidência de afecções da coluna cervical que comprometem significativamente a locomoção de equinos atletas, além da dificuldade do diagnóstico pelos exames físico e radiográfico (Dyson, 2003; Fonseca et al., 2006; Mac Kay, 2006), o presente estudo buscou descrever a anatomia da região cervical de equinos sem sinais de alterações a partir de imagens obtidas pela tomografia computadorizada helicoidal, proporcionando um atlas tomográfico de suporte para o diagnóstico de afecções da coluna cervical de equinos.

\section{MATERIAL E MÉTODOS}

Foram utilizadas três peças anatômicas da região cervical de equinos adultos, machos, da raça Quarto de Milha, que foram a óbito por enfermidades não correlacionadas ao presente estudo. As imagens tomográficas foram adquiridas em um aparelho de tomografia computadorizada helicoidal da marca Shimadzu, modelo SCT7800TC, com $120 \mathrm{kV}$ e $160 \mathrm{~mA}$ em cortes axiais contínuos de $5 \mathrm{~mm}$ de espessura por $1 \mathrm{~mm}$ de espaçamento, desde a extremidade da tuberosidade occipital até a epífise cranial da primeira vértebra torácica. Todas as imagens foram obtidas em filtros para tecido ósseo em cortes axiais e, posteriormente, avaliadas e descritas de acordo com a Nomina Anatômica Veterinária, em estudo comparativo com alguns atlas anatômicos (Lahunt e Habel, 1986; Popesko, 1997; Clayton e Flood, 2002; König e Liebich, 2002).

\section{RESULTADOS}

Os resultados encontram-se nas Fig. 1 a 9, onde cada estrutura anatômica está indicada por números arábicos, os quais são descritos nas correspondentes legendas, bem como nas particularidades redigidas ao longo do texto. A coluna cervical inclui sete vértebras (C1-C7) articuladas entre si na região dorsal pelos processos articulares. Estas articulações são do tipo sinovial e, para auxiliar na estabilidade articular, possuem ligamentos e músculos adjacentes, que não são visibilizados e diferenciados pela tomografia. As imagens da região occipitoatlantoaxial correspondem ao maior número de imagens neste estudo em razão de suas particularidades anatômicas, pois as demais vértebras apresentam formatos e estruturas similares.
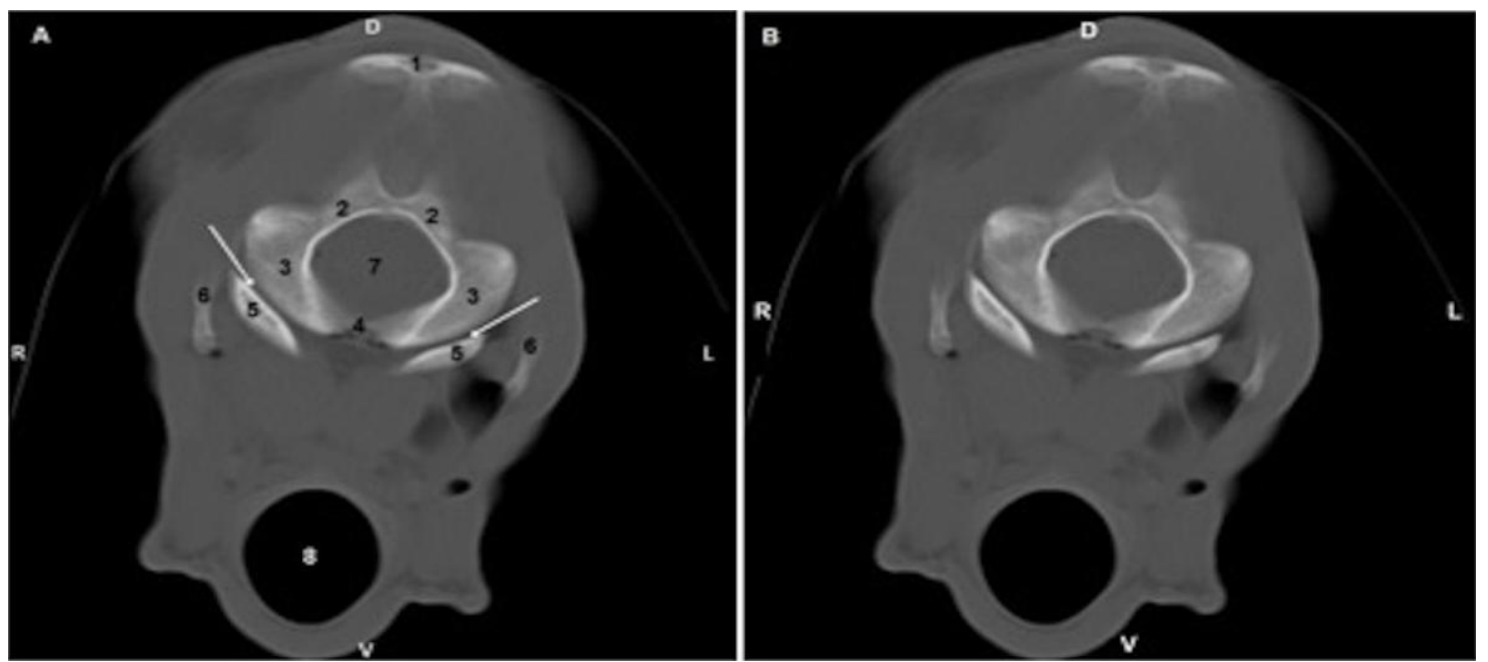

Figura 1. Equino. (D) Dorsal, (V) ventral, (R) direita, (L) esquerda. Imagem de tomografia computadorizada helicoidal em plano axial da região cervical no nível de transição atlantooccipital em janela óssea (WW: 2590; WL:512) (A e B). (1) Crista nucal; (2) arco dorsal do atlas; (3) início da asa do atlas; (4) faceta articular caudal com fóvea do dens; (5) côndilos do occipital; (6) processo paracondilar esquerdo e direito do occipital; (7) canal medular/medula espinhal; (8) traqueia; (setas brancas, Fig. A) espaço articular da articulação atlantooccipital; (10). As áreas luscentes entremeadas aos tecidos representam ar (artefato pos-mortem). 


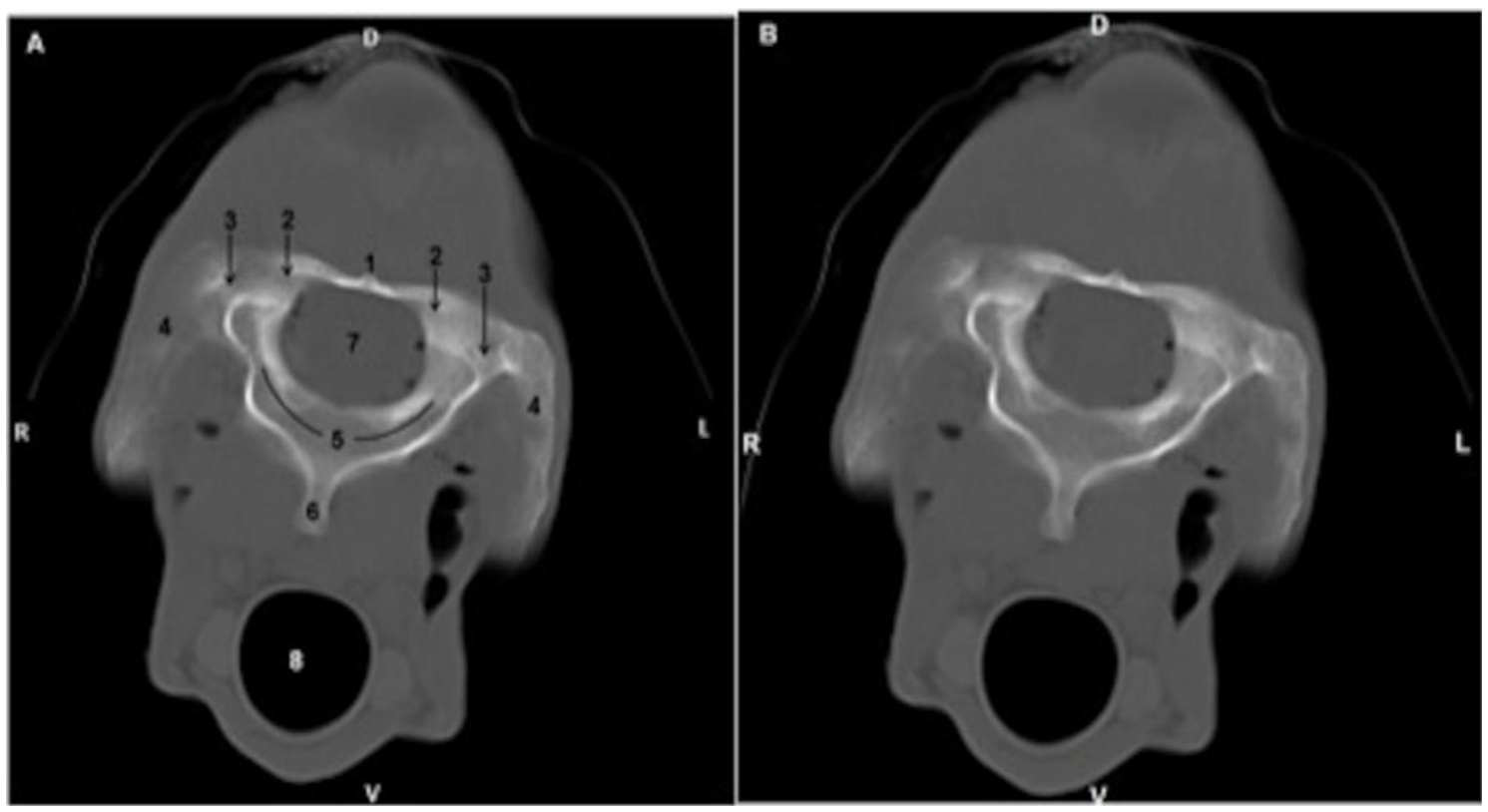

Figura 2. Equino. (D) Dorsal, (V) ventral, (R) direita, (L) esquerda. Imagem de tomografia computadorizada helicoidal em plano axial da região cervical no nível da atlas $(\mathrm{C} 1)$ em janela óssea (WW: 2590; WL:512) (A e B). (1) Tubérculo dorsal do arco dorsal; (2) forame vertebral lateral; (3) forame alar; (4) asas do atlas; (5) arco ventral do atlas; (6) tubérculo ventral; (7) canal medular/medula espinhal; (8) traqueia. As áreas luscentes entremeadas aos tecidos representam ar (artefato pos-mortem).

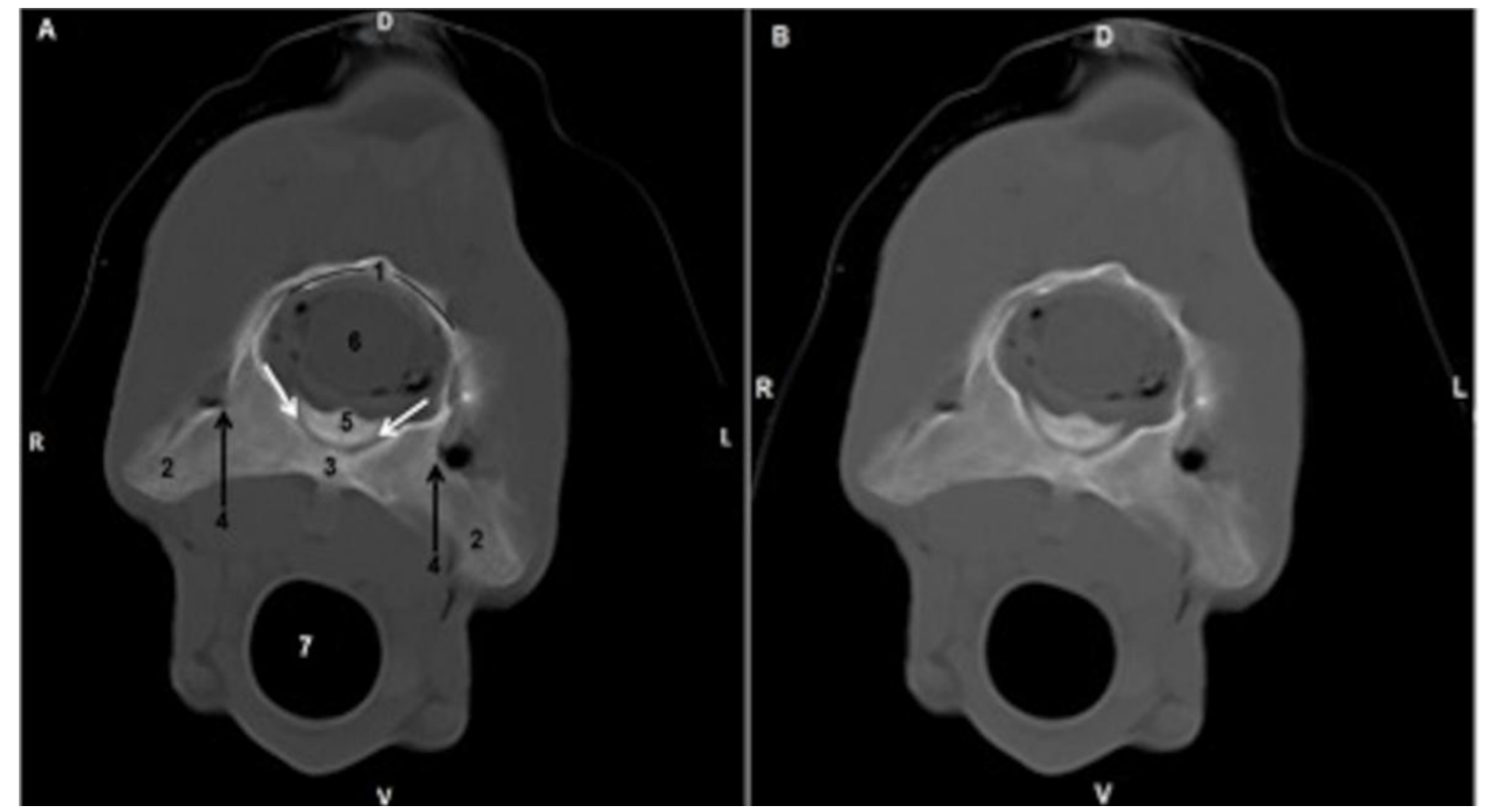

Figura 3. Equino. (D) Dorsal, (V) ventral, (R) direita, (L) esquerda. Imagem de tomografia computadorizada helicoidal em plano axial da região cervical no nível da transição atlantoaxial em janela óssea (WW: 2590; WL:512) (A e B). (1) Arco dorsal; (2) asas do atlas; (3) faceta articular caudal com fóvea do dens; (4) forame transverso; (5) processo odontoide do áxis - dens; (6) canal medular/medula espinhal; (7) traqueia; (setas brancas) articulação atlantoaxial. As áreas luscentes entremeadas aos tecidos representam ar (artefato pos-mortem). 


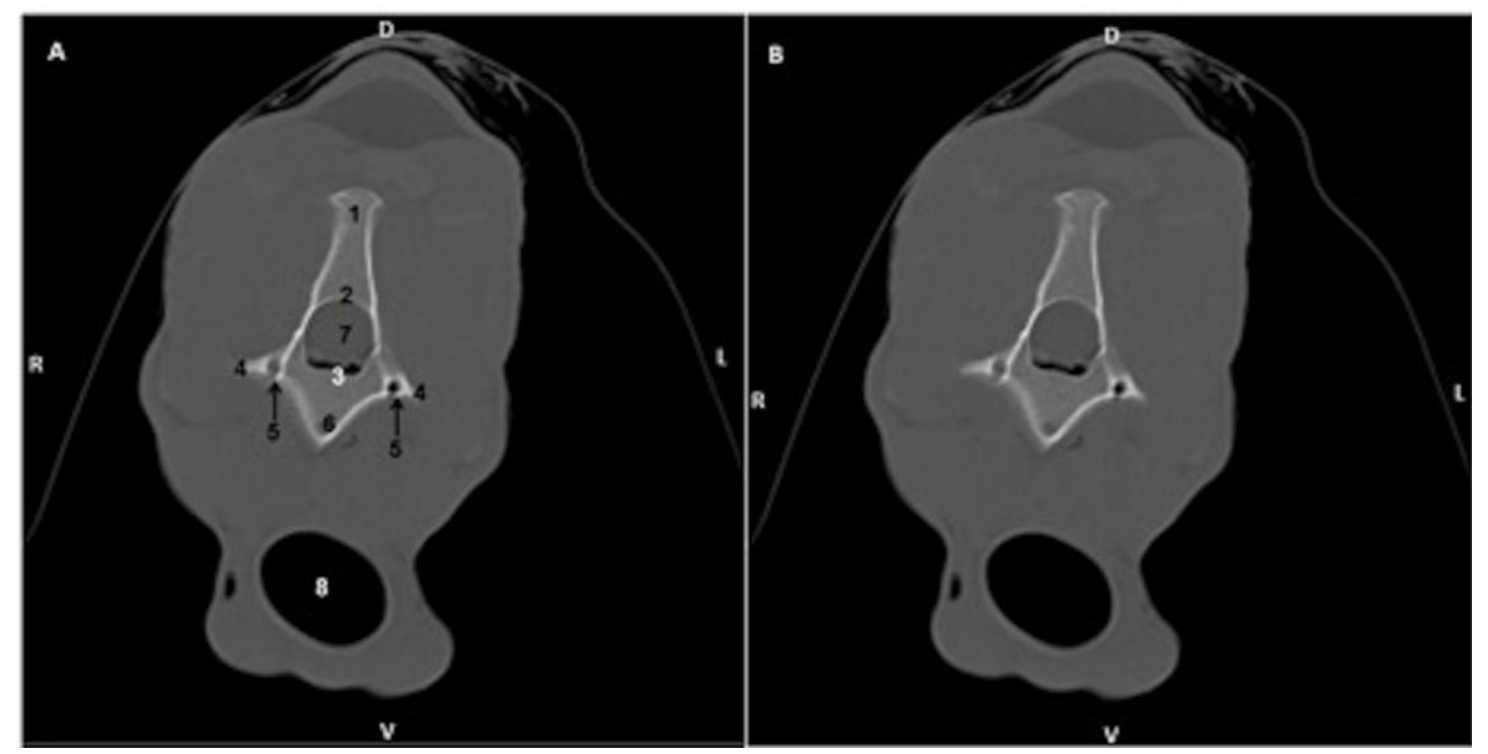

Figura 4. Equino. (D) Dorsal, (V) ventral, (R) direita, (L) esquerda. Imagem de tomografia computadorizada helicoidal em plano axial da região cervical no nível da áxis (C2) em janela óssea (WW: 2590; WL:512) (A e B). (1) Processo espinhoso; (2) arco dorsal; (3) arco ventral; (4) processo transverso; (5) forame vertebral lateral; (6) crista ventral; (7) canal medular/medula espinhal; (8) traqueia. As áreas luscentes entremeadas aos tecidos representam ar (artefato pos-mortem).

As duas primeiras vértebras - atlas e áxis - são modificadas para acomodar o movimento e o peso da cabeça. O atlas é achatado e não possui corpo vertebral ou processos articulares; é composto por um arco dorsal e ventral e proeminências laterais denominadas asas do atlas (Fig. 1 e 2). Na superfície do seu arco ventral, origina-se uma fóvea que acomoda o processo odontoide do áxis (Fig. 1). O áxis possui um largo processo espinhoso dorsal e uma projeção cranial que se estende até o atlas, denominada processo odontoide ou dens (Fig. 3 e 4 ).

As vértebras cervicais C3, C4, C5 e C6 são alongadas, com processos espinhosos rudimentares e grandes processos transversos divididos em duas faces largas que possuem um forame (forame transverso) para passagem de raízes nervosas. Essas vértebras possuem um formato ligeiramente retangular e epífises craniais e caudais. Há também uma crista ventral mediana que se torna mais proeminente na região caudal. Como essas vértebras apresentam estruturas e formatos similares, são representadas neste estudo pela terceira vértebra cervical (Fig. 6). A sétima vértebra é diferenciada das demais por apresentar um corpo vertebral ligeiramente menor, mais largo e achatado, com um pequeno processo espinhoso e processos transversos sem divisões e forame (Fig. 9). Os processos articulares craniais e caudais de $\mathrm{C} 3$ a C7 formam pares de articulações consideradas verdadeiras, ou seja, as articulações sinoviais são identificadas nas imagens como uma linha hipoatenuante na transição das vértebras (Fig. 5, 7 e 8$)$.

Os músculos, tendões e ligamentos da região cervical são pobremente definidos na imagem tomográfica, sendo evidenciadas apenas as estruturas maiores e mais densas.

\section{DISCUSSÃO}

Em humanos, a utilização da tomografia computadorizada para a avaliação da coluna vertebral é considerada de alta eficácia e precisão (LeBlang e Nuñez, 1999; Mayhew, 1999). Na medicina veterinária, essa técnica é descrita com sucesso para a avaliação da coluna vertebral de cães (Ohlerth e Scharf, 2007). 


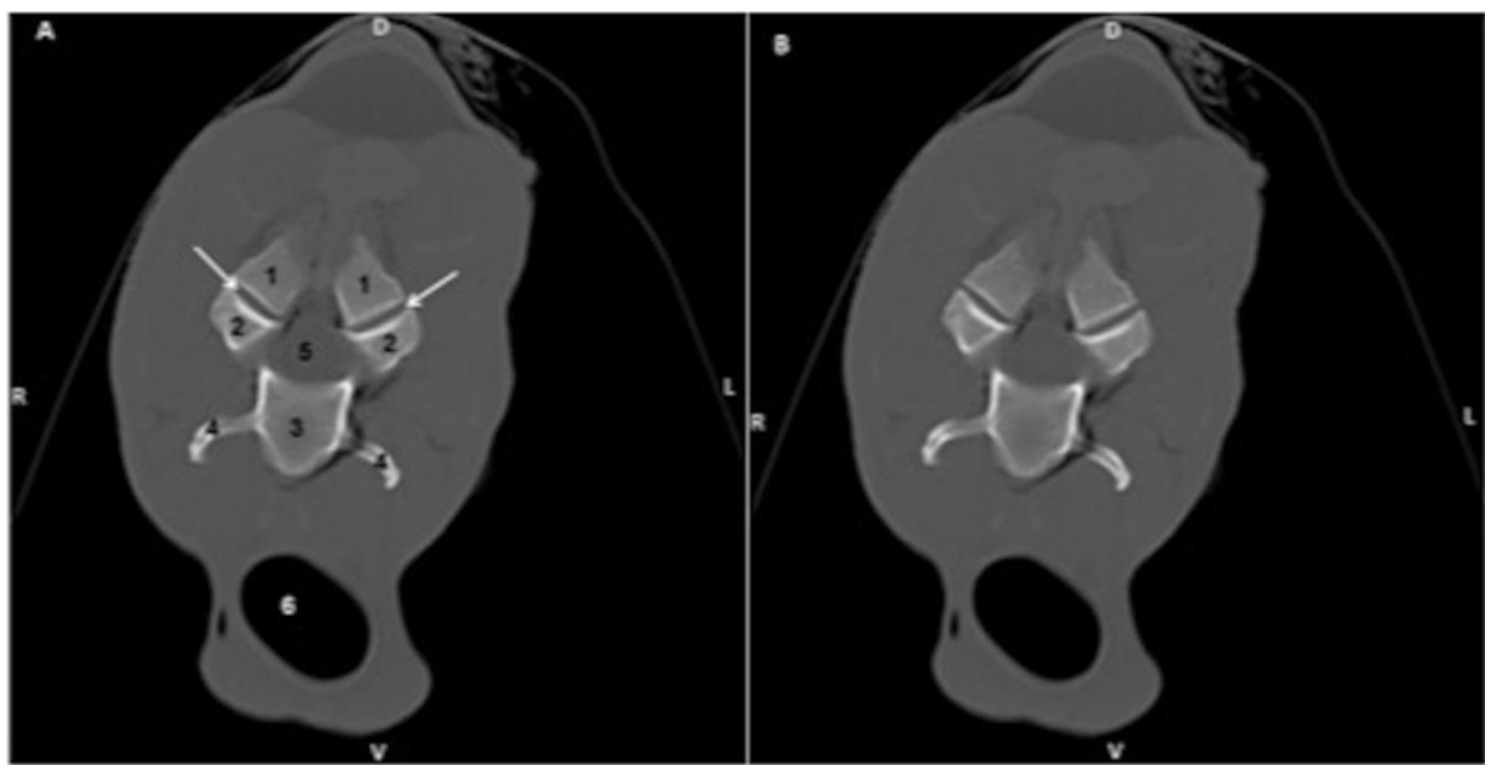

Figura 5. Equino. (D) Dorsal, (V) ventral, (R) direita, (L) esquerda. Imagem de tomografia computadorizada helicoidal em plano axial da região cervical no nível da transição áxis - C3 em janela óssea (WW: 2590; WL:512) (A e B). (1) Processo articular caudal de áxis; (2) processo articular cranial da terceira vértebra cervical; (3) corpo da terceira vértebra cervical; (4) tubérculo ventral do processo transverso da terceira vértebra cervical; (5) canal medular/medula espinhal; (6) traqueia; (setas brancas) cavidade articular. As áreas luscentes entremeadas aos tecidos representam ar (artefato pos-mortem).

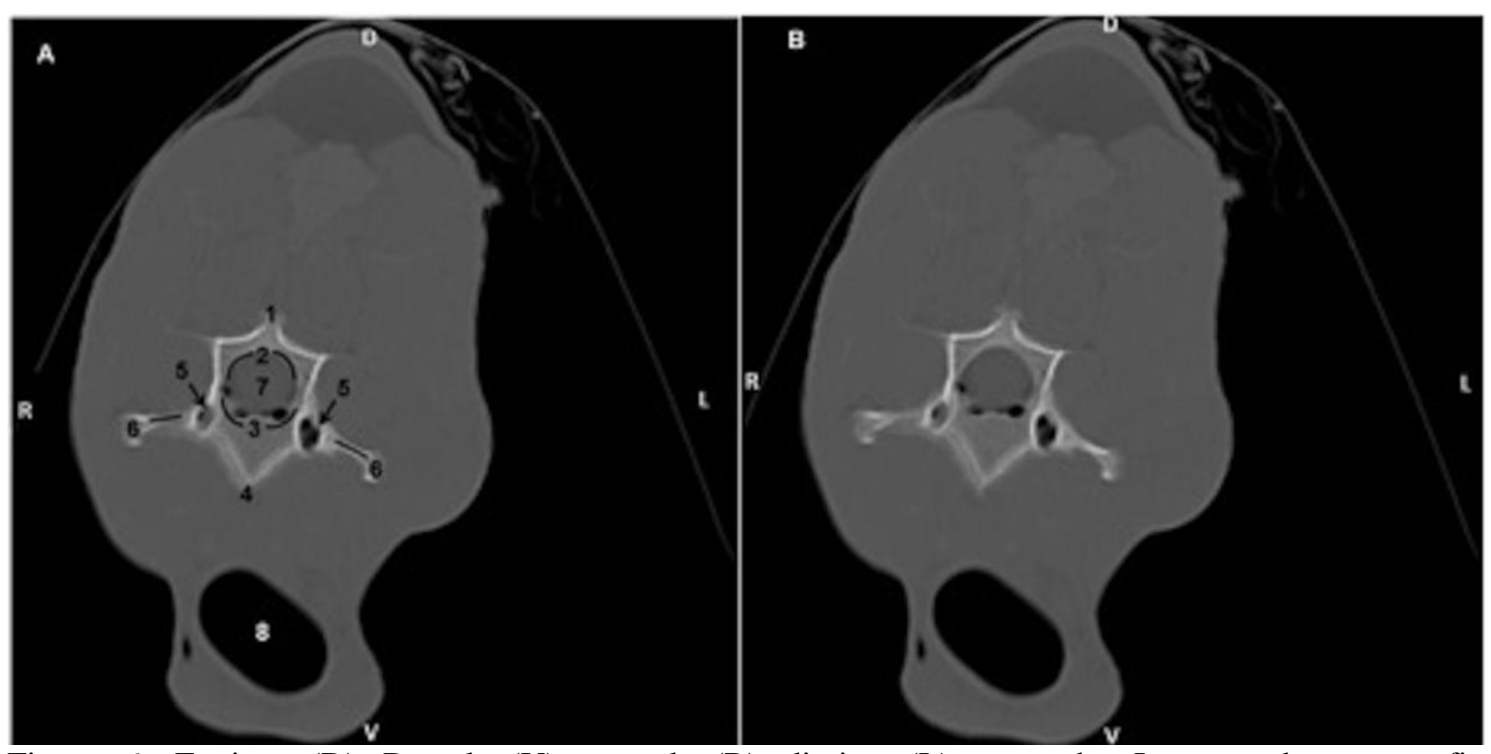

Figura 6. Equino. (D) Dorsal, (V) ventral, (R) direita, (L) esquerda. Imagem de tomografia computadorizada helicoidal em plano axial da região cervical no nível da terceira vértebra (C3) em janela óssea (WW: 2590; WL:512) (A e B). (1) Processo espinhosos; (2) arco dorsal; (3) arco ventral; (4) crista ventral; (5) forame transverso; (6) processo transverso; (7) canal medular/medula espinhal; (8) traqueia. As áreas luscentes entremeadas aos tecidos representam ar (artefato pos-mortem). 

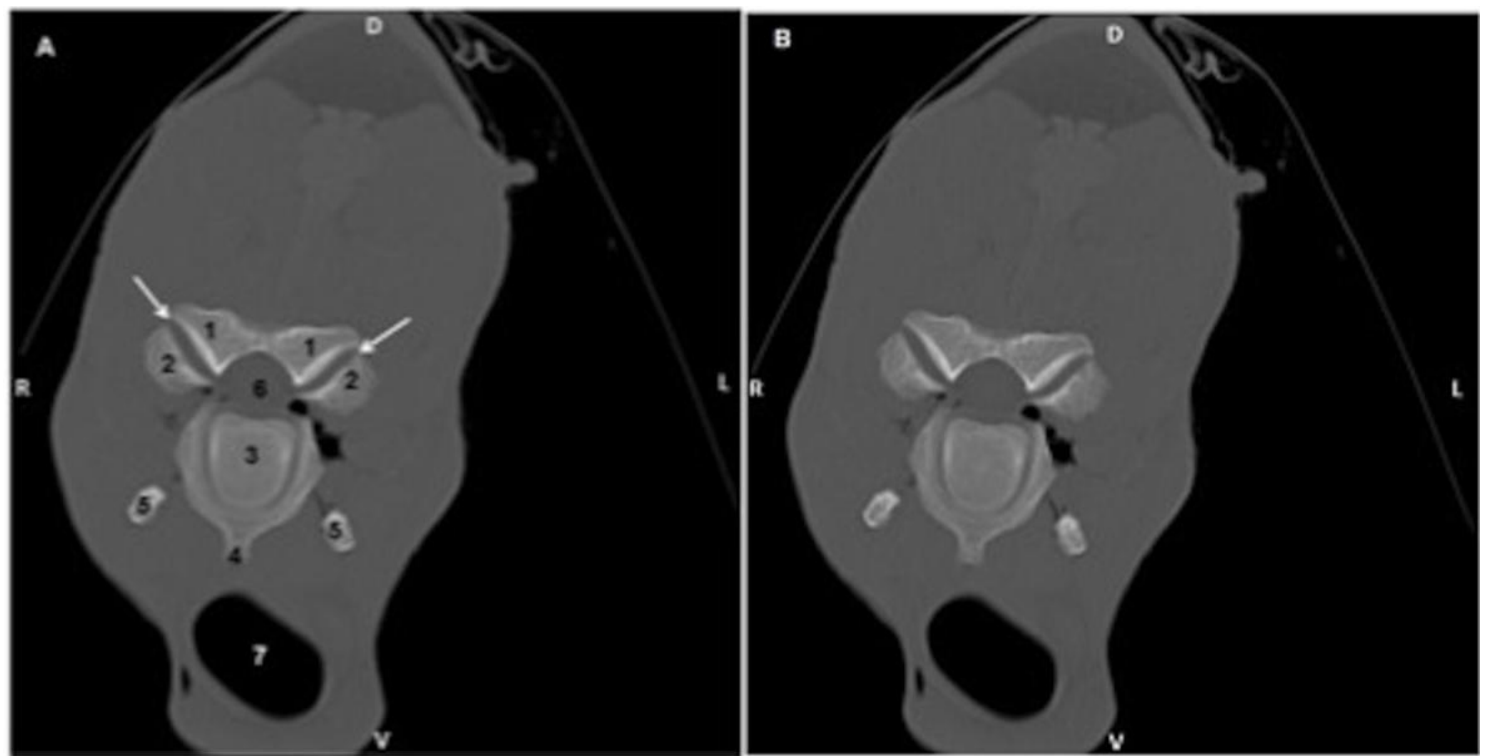

Figura 7. Equino. (D) Dorsal, (V) ventral, (R) direita, (L) esquerda. Imagem de tomografia computadorizada helicoidal em plano axial da região cervical no nível da transição da terceira para a quarta vértebra (C3-C4) em janela óssea (WW: 2590; WL:512) (A e B). (1) Processo articular caudal da terceira vértebra cervical; (2) processo articular cranial da quarta vértebra cervical; (3) corpo da quarta vértebra cervical; (4) crista ventral da quarta vértebra cervical; (5) tubérculo ventral do processo transverso da quarta vértebra cervical; (6) canal medular/medula espinhal; (7) traqueia; (setas brancas) cavidade articular. As áreas luscentes entremeadas aos tecidos representam ar (artefato pos-mortem).
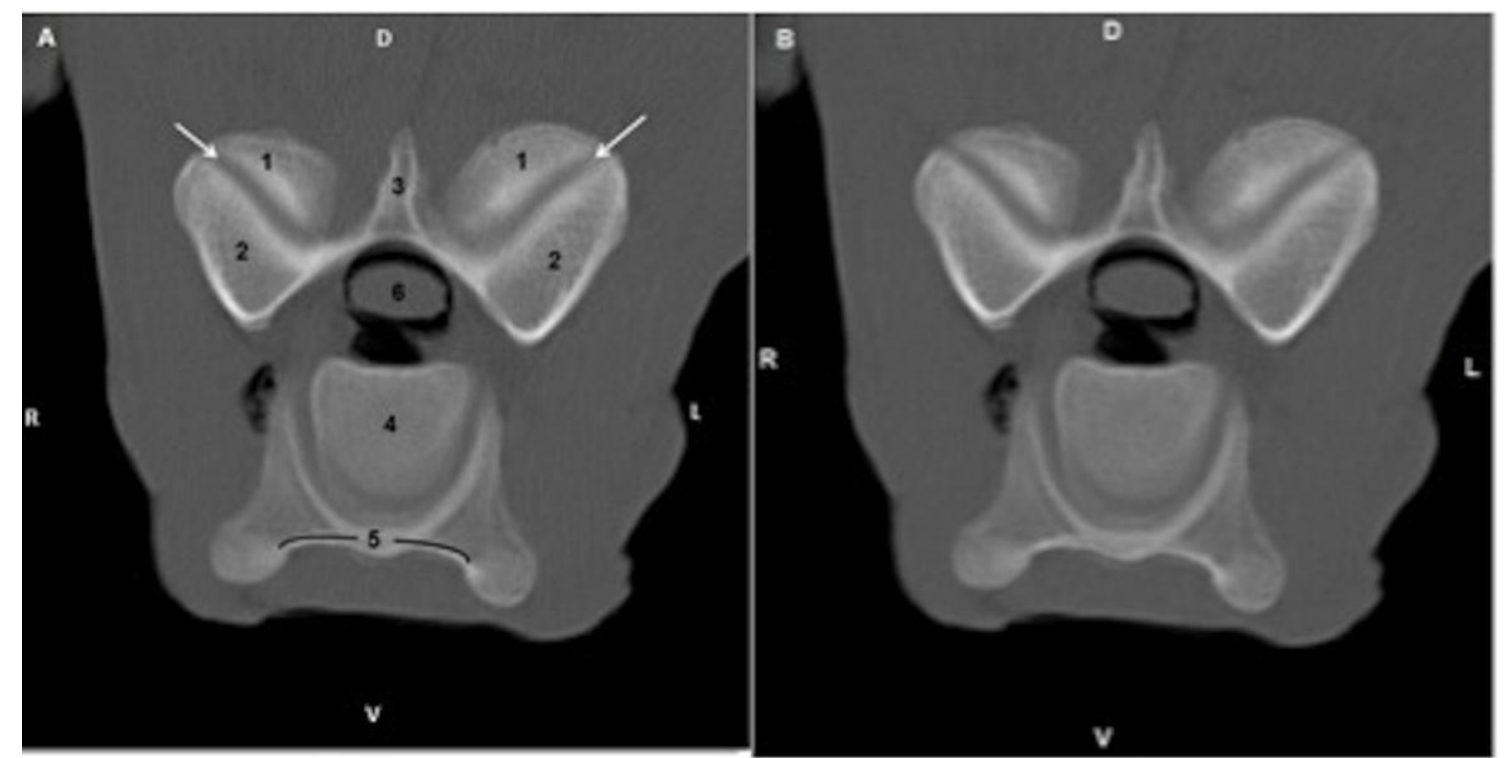

Figura 8. Equino. (D) Dorsal, (V) ventral, (R) direita, (L) esquerda. Imagem de tomografia computadorizada helicoidal em plano axial da região cervical no nível da transição da sexta para a sétima vértebra (C6-C7) em janela óssea (WW: 2590; WL:512) (A e B). (1) Processo articular caudal da sexta vértebra cervical; (2) processo articular cranial da sétima vértebra cervical; (3) processo espinhoso da sétima vértebra cervical; (4) corpo da sétima vértebra cervical; (5) crista ventral da sétima vértebra cervical; (6) canal medular/medula espinhal; (setas brancas) cavidade articular. As áreas luscentes entremeadas aos tecidos representam ar (artefato pos-mortem). 

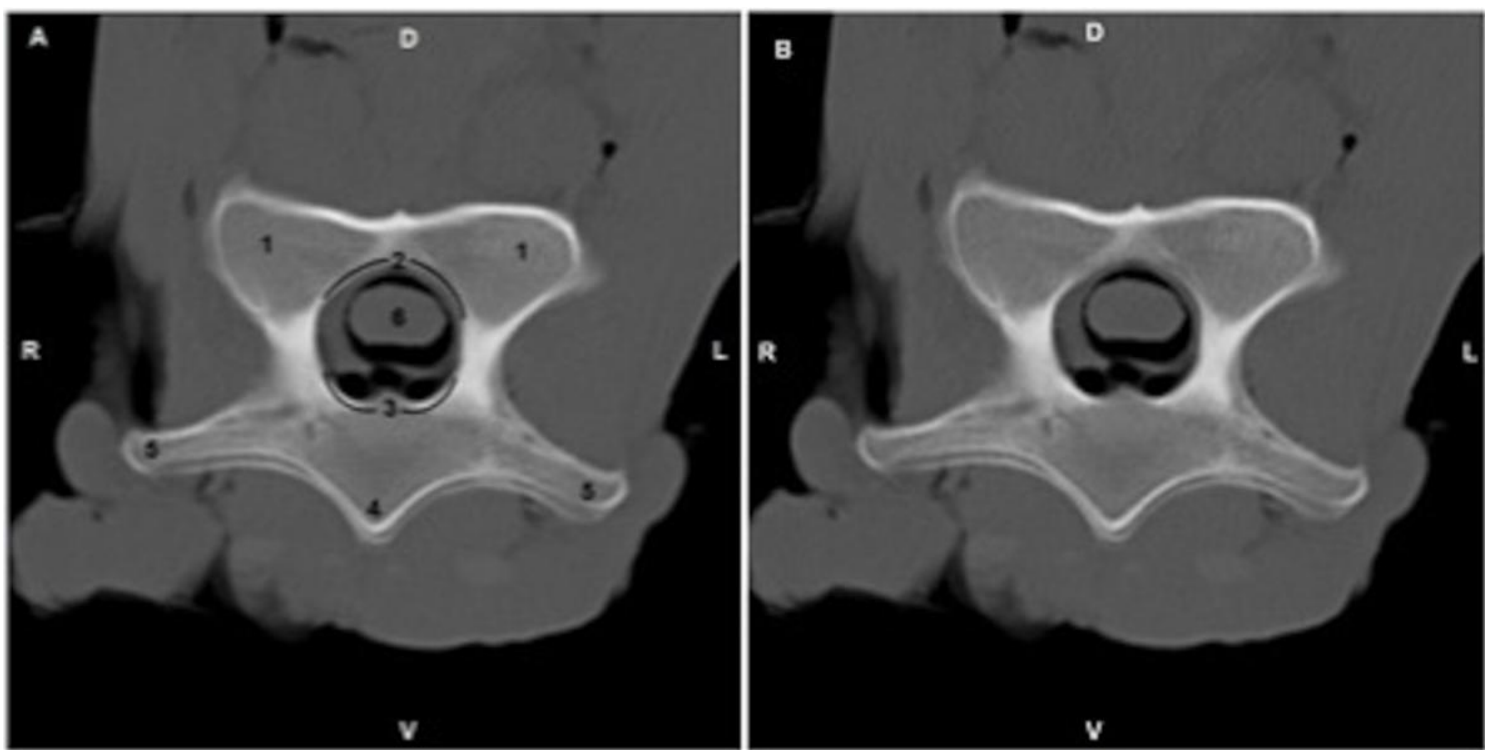

Figura 9. Equino. (D) Dorsal, (V) ventral, (R) direita, (L) esquerda. Imagem de tomografia computadorizada helicoidal em plano axial da região cervical no nível da sétima vértebra (C7) em janela óssea (WW: 2590; WL:512) (A e B). (1) Processo articular cranial da sétima vértebra cervical; (2) arco dorsal; (3) arco ventral; (4) crista ventral; (5) processo transverso; (6) canal medular/medula espinhal. As áreas luscentes entremeadas aos tecidos representam ar (artefato pos-mortem).

A imagem diagnóstica é fundamental para a investigação da claudicação em equinos de esporte, segundo Dyson (2003), sendo a tomografia computadorizada um método superior quando comparada ao exame radiográfico, porém seu uso na avaliação da região cervical ainda não é muito relatado. Considerando-se que a claudicação em equinos atletas pode estar diretamente relacionada ao acometimento da região cervical, e à dificuldade de identificar o local exato da dor pelos exames físico e radiográfico (Berg et al., 2002; Fonseca et al., 2006), torna-se importante a investigação mais precisa desta região.

A imagem tomográfica oferece vantagens sobre a radiografia, principalmente por eliminar as limitações causadas pela sobreposição de estruturas adjacentes encontradas no exame radiográfico (Dyson, 2003; MacKay, 2006). Porém, é importante lembrar que um exame não substitui o outro, tornando-os complementares para um diagnóstico mais apurado e específico. Dessa forma, a tomografia computadorizada pode ser utilizada para identificar e descrever adequadamente a extensão de alterações ósseas subjacentes, visto que a boa resolução espacial, o contraste obtido com este exame e os diversos planos anatômicos fornecidos para avaliação tornam-no exame de escolha para estudo da morfologia óssea vertebral (Dyson, 2003; Mac Kay, 2006; Withers et al., 2009).

A avaliação dos tecidos moles é mais bem realizada por meio de outro método de imagem, como a ultrassonografia, sendo a associação dela com a tomografia computadorizada de grande valia para pesquisa e diagnóstico de afecções.

\section{CONCLUSÕES}

O estudo fornece descrições anatômicas que aprimoram os conhecimentos sobre a imagem tomográfica aplicada à região cervical de equinos e estimula o uso dessa ferramenta diagnóstica na medicina equina, o que possivelmente irá aumentar a qualidade do diagnóstico das afecções vertebrais cervicais ou mesmo reduzir o percentual de falhas no diagnóstico. É importante ressaltar que cada método de imagem é único e insubstituível e que a associação desses contribui para aumentar a precisão diagnóstica. 


\section{REFERÊNCIAS}

BERG, L.C.; NIELSEN, J.V.; THOEFNER, M.B. et al. Ultrasonography of equine cervical region: a descriptive study in eight horses. Equine Vet. J., v.35, p.647-655, 2002.

BUTTLER, J.A.; COLLES C.M.; DYSON, S.J. et al. The spine. In: Clinical radiology of the horse. 2.ed. Oxford: Blackwell Science, 2000. p.403-430.

CLAYTON, H.M.; FLOOD, P.F. Coluna cervical. In: __. Atlas colorido de anatomia aplicada dos grandes animais. Barueri: Manole, 2002. p.27-35.

DIMOCK, A.N.; PUCHALSKI, S.N. Cervical radiology. Equine Vet. Educ., v.22, p.83-87, 2010.

DYSON, S.J. The cervical spine and soft tissues of the neck. In: ROSS, M.W.; DYSON, S.J. Diagnosis and management of lameness in the horse. St Louis: Saunders, 2003. p.522-531.

FONSECA, B.P.A.; ALVES, A.L.G.; NICOLETTI, J.L.M. et al. Thermography and ultrasonography in back pain diagnosis of equine athletes. J. Equine Vet. Sci., v.26, p.507-516, 2006.

GOLLOB, E.; EDINGER, H.; STANEK, C. et al. Ulrasonographic investigation of the atlantooccipital articulation in the horses. Equine Vet. J., v.34, p.44-50, 2002.

HAUSSLER, K.K. Equine Chiropractic: general principles and clinical applications. In: AMERICAN ASSOCIATION OF EQUINE PRACTITIONERS, 2000, Proceedings..., v.46, p.84-93, 2000.

KÖNIG, H.E.; LIEBICH, H.G. Coluna Vertebral. In. __. Anatomia dos animais domésticos: texto e atlas colorido. São Paulo: Artmed, 2002. v.1, p.72-79.
LAHUNT, A.; HABEL, R.E. Applied veterinary anatomy. Philadelphia: Saunders, 1986. p.67-70.

LEBLANG, S.D.; NUÑEZ, D.B. Helical CT of cervical spine and soft tissue injuries of the neck. Radiol. Clin. North Am., v.37, p.515-532, 1999.

MACKAY, R.J. The vertebral column. In: AUER, J.A.; STICK, J.A. Equine surgery. 3.ed. St Louis: Saunders, 2006. p.642-655.

MAYHEW, G.J. The disease spinal cord. In: AMERICAN ASSOCIATION OF EQUINE PRACTITIONERS, 1999, Lexington. Proceedings..., Lexington:AAEP, 1999. v.45, p.67-84.

MATTOON, J.S. Imaging of equine neurological disease. In: EUROPEAN ASSOCIATION OF VETERINARY DIAGNOSTIC IMAGING, 2007, Porto Carras. Annual Meeting... Porto Carras, 2007. p.20-22.

POPESKO, P. Coluna vertebral. In: POPESKO, P. Atlas de anatomia topográfica dos animais domésticos. São Paulo: Manole, 1997. p.160169.

RUSH, B.R.; GRADY, J.A. Cervical stenotic myelopathy. Equine Diag. Treat., v.2, p.6-10, 2002.

OHLERTH, S.; SCHARF, G. Computed tomography in small animals - Basic principles and state of the art applications. Vet. J., v.173, p.254-271, 2007.

WITHERS, J.M.; VOÛTE, L.C.; LISCHER C.J. Multi-modality diagnostic imaging of a cervical articular process fracture in a Thoroughbred horses including a novel C-Arm imaging technique. Equine Vet. Educ., v.21, p.540-545, 2009. 